\title{
Virtual model of an automated system for the storage of collected waste
}

\author{
George Enciu ${ }^{1}$, Adrian Popescu ${ }^{1}$, Cicerone Laurentiu Popa ${ }^{1, *}$, and Costel Emil Cotet $^{1}$ \\ ${ }^{1}$ University Politehnica of Bucharest, MSP Department, Spl. Independentei 313, Bucharest, Romania
}

\begin{abstract}
One of the problems identified in waste collection integrated systems is the storage space. The design process of an automated system for the storage of collected waste includes finding solutions for the optimal exploitation of the limited storage space, seen that the equipment for the loading, identification, transport and transfer of the waste covers most of the available space inside the integrated collection system. In the present paper a three-dimensional model of an automated storage system designed by the authors for a business partner is presented. The storage system can be used for the following types of waste: plastic and glass recipients, aluminium cans, paper, cardboard and WEEE (waste electrical and electronic equipment). Special attention has been given to the transfer subsystem, specific for the storage system, which should be able to transfer different types and shapes of waste. The described virtual model of the automated system for the storage of collected waste will be part of the virtual model of the entire integrated waste collection system as requested by the beneficiary.
\end{abstract}

\section{Introduction}

In the context of technological progress and the society evolution we must have a strict waste management so as to ensure the continuous development and protection of the planet's resources. For this, it is necessary that any company provide means for collecting waste, which should be as simple as possible, and with continuous accessibility. Such a means for the waste continuous collection represents the automated collection and storage system [1, 2-3].

In its current configuration, the waste collection system contains a RVM (Reverse Vending Machine) for plastic recipients, glass recipients and aluminium cans, different modules for collecting: plastic film, plastic bags, paper, cardboard, batteries, small and big electronics and appliances. These modules are not automated; two operators are receiving the collected waste. The operators are identifying and weighing the WEEEs and are transporting the WEEEs to the storage area. In this paper we intend to present a virtual model of an automated system for the storage of collected waste (plastic and glass recipients, aluminium cans, paper, cardboard and WEEEs) as a part of the virtual model of the entire integrated waste collection system.

\footnotetext{
*Corresponding author: laur.popa79@gmail.com
} 
The automated storage system must permit the transportation and storage of all waste types (large home appliances, large blocks of compacted paper and cardboard and containers), with the possibility of quick access, without the intervention of human operators in the storage area.

The main advantages of using an automated waste storage system in the proposed application are the following

- reduced time for the storage and access to the stored waste;

- management of the stored waste;

- vertical storage availability which leads to reduced storage space.

The types of waste that will be stored via the automated storage system integrated into the application are divided into the following categories:

- Large home appliances: refrigerators, washing machines, TVs etc.

- Mid-size home appliances: microwave ovens, desktop computers, laptops etc.

- Containers that can contain small home appliances such as tablets, mouse, keyboards, phones etc. and pressed aluminium cans.

- Blocks of compacted paper and cardboard.

Examples of such systems that may be used in the software application for collecting and storing waste are presented in Figure 1.
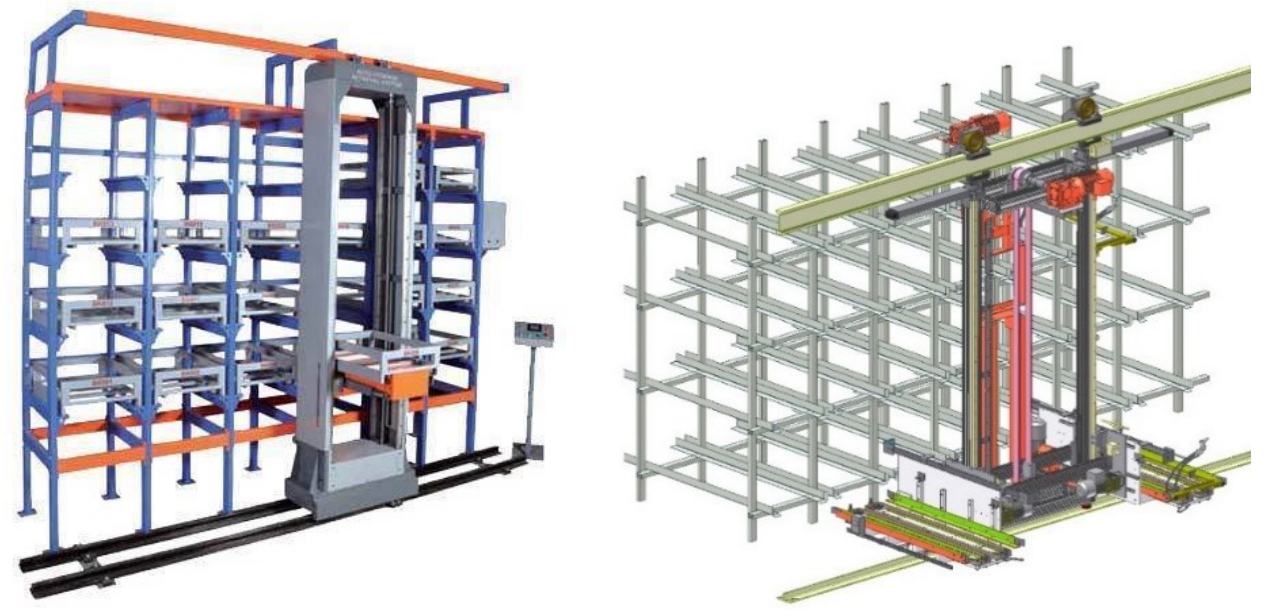

Fig.1. Examples of automated storage systems

The designed storage system must be justified in terms of investment and operating costs by ensuring an adequate level of performance.

Therefore, the physical capacity specific to the storage system must be greater than the maximum volume of waste that is expected to be stored. The surface of the storage area designed will be of $9.8 \mathrm{~m}^{2}$ and the height will be of $6 \mathrm{~m}$.

The space afferent to the lane specific to the transport - transfer system which carries out the storage operation automatically, often occupies more space than the usable storage capacity.

Taking into account the performance that the storage system as part of the integrated system for the waste collection and disposal must meet and the types of parts that will be stored, the transport- transfer system specific to the storage system designed will need to meet the above demands.

Since using an automated storage and waste collection system has as main purposes to remove the human factor and a very good planning and use of storage space, respectively, we will use as storage strategy, at least in a first phase, the predetermined storing [4-5]. 


\section{Equipment in the waste collection system}

A possible variant of positioning the equipment into the waste automated collection system and the waste disposal station is shown in Figure 2.

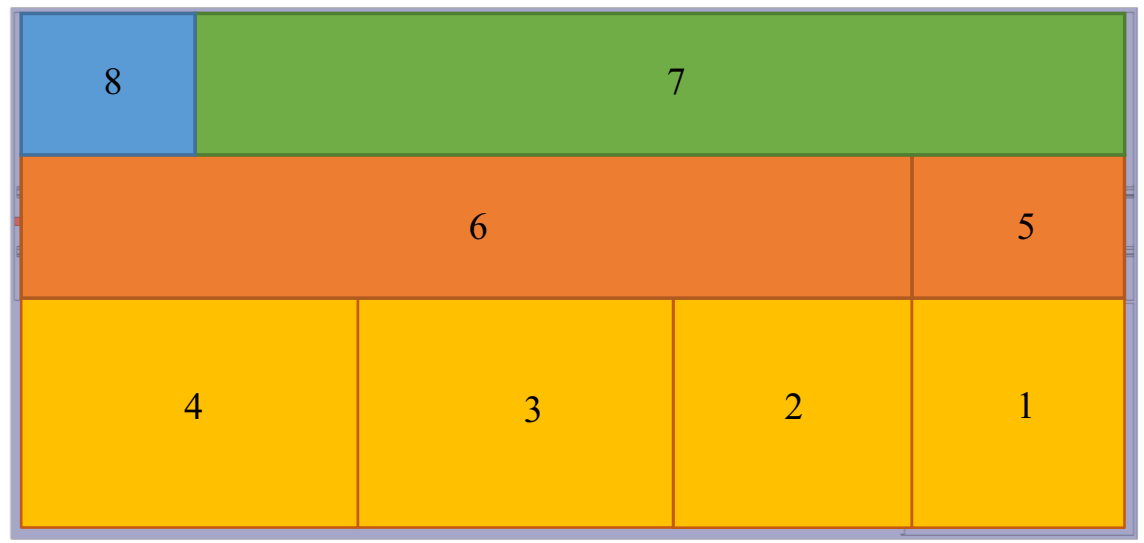

Fig. 2. Positioning the equipment in the waste collection and storage system

The correspondence between the positions shown on the Figure 2 sketch and the names of equipment used in the waste collection and storage system is presented in Table 1.

Table 1. Equipment in the waste collection system.

\begin{tabular}{|c|c|}
\hline Position & Equipment name/zone \\
\hline 1 & Input station for large home appliances wastes \\
\hline 2 & Input station for small home appliances wastes \\
\hline 3 & $\begin{array}{c}\text { Input station for paper and cardboard wastes including the pressing } \\
\text { machine for compacting and making the paper blocks }\end{array}$ \\
\hline 4 & $\begin{array}{r}\text { Input station for plastic recipients, glass recipients, cans, including the } \\
\text { equipment for selecting and compacting the waste }\end{array}$ \\
\hline 5 & Transport transfer system included in the automated storage system \\
\hline 6 & Access lane for the transport transfer system \\
\hline 7 & $\begin{array}{c}\text { Waste storage proper area made up of a rack with 27 specific places for } \\
\text { storage }\end{array}$ \\
\hline 8 & Output station for stored wastes \\
\hline
\end{tabular}

Positions 1, 2, 3 and 4 correspond to entering into the system of the waste in correlation with the description in Table 1. Each station will be previously fuelled with a support pallet for positioning the parts that will be stored (large home appliances, compacted cardboard / paper blocks or containers with glass recipients, plastic recipients or aluminium cans).

The input station into the system for large home appliances wastes (Figure 3) is equipped with a conveyor allowing the support pallet positioning and blocking in a fixed position when the home appliances waste is fed to avoid theft. When the access for home appliances feeding is allowed, the access gate that separates the input station from the 
storage system is closed; it will open only after the waste identification and weighting and after the feeding access gate will close. For the input stations corresponding to positions 2,3 , and 4 the feeding with small home appliances waste, cardboard / paper is performed through small access doors, outside the waste collection storage system and, respectively, glass recipients, plastic recipients and aluminium cans are received, identified and sorted using a RVM equipment.
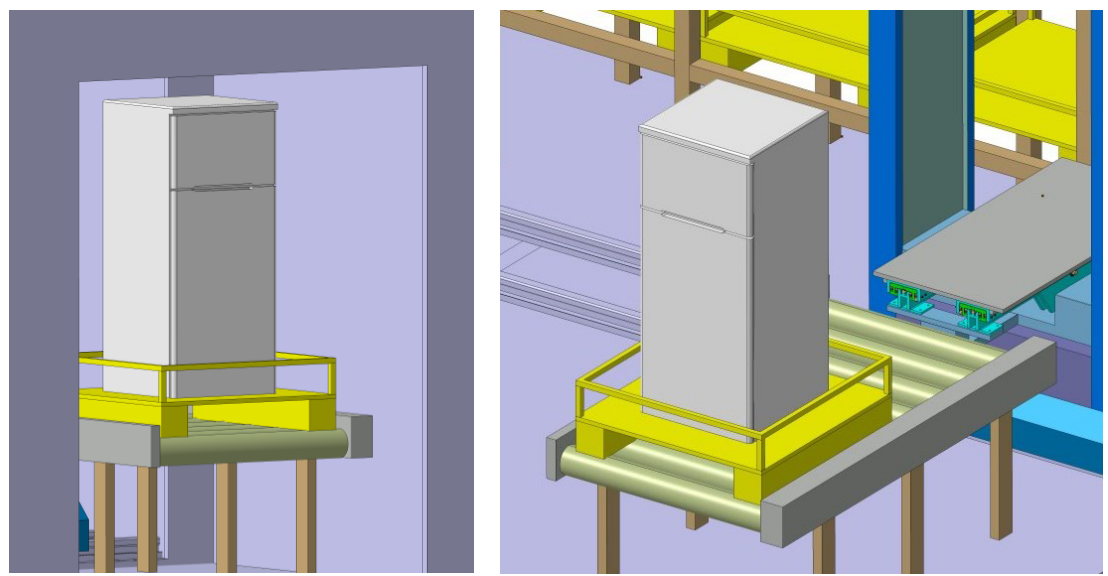

Fig. 3. Input station for large home appliances wastes

\section{Wastes automated storage system}

The waste storage system (Figure 4) comprises three main elements: storage structure, the transport-transfer system and the input-output stations [6-8].

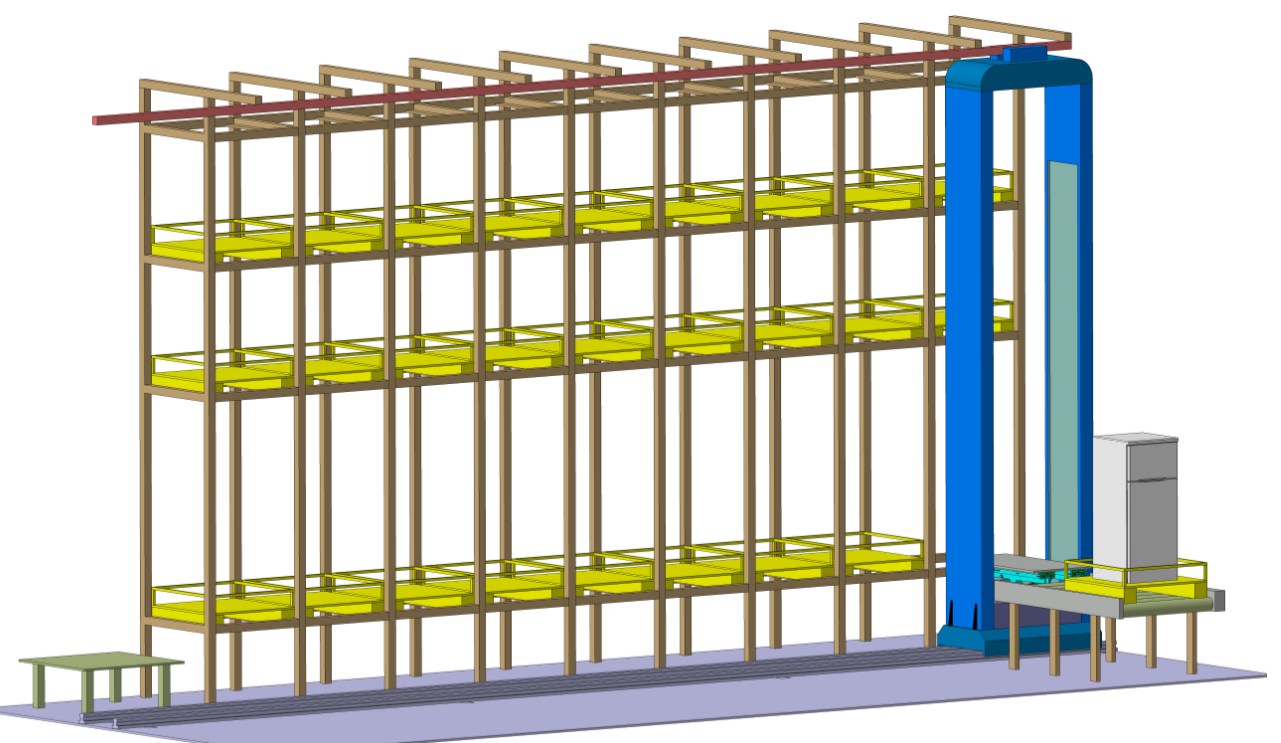

Fig. 4. Automated storage system 


\subsection{Storage structure}

The storage structure consists of a shelving system used for the waste storage (Figure 5). The 27 specific storage places ( 3 levels with 9 places on each level) are of different sizes, so in base places there will be stored as appropriate, large electronic waste (refrigerators, washing machines, TVs etc.) and on the other places from levels 2 and 3 there will be stored blocks of paper or cardboard, containers with small electronic wastes, glass recipients, cans and plastic recipients. The storage places have a standard structure and to store different types of waste a support pallet is used. In the base places, there can be stored home appliances wastes with the maximum height of $2 \mathrm{~m}$, and in the places afferent to levels 2 and 3, there can be deposited containers or paper/cardboard blocks with a maximum height of $1 \mathrm{~m}$.

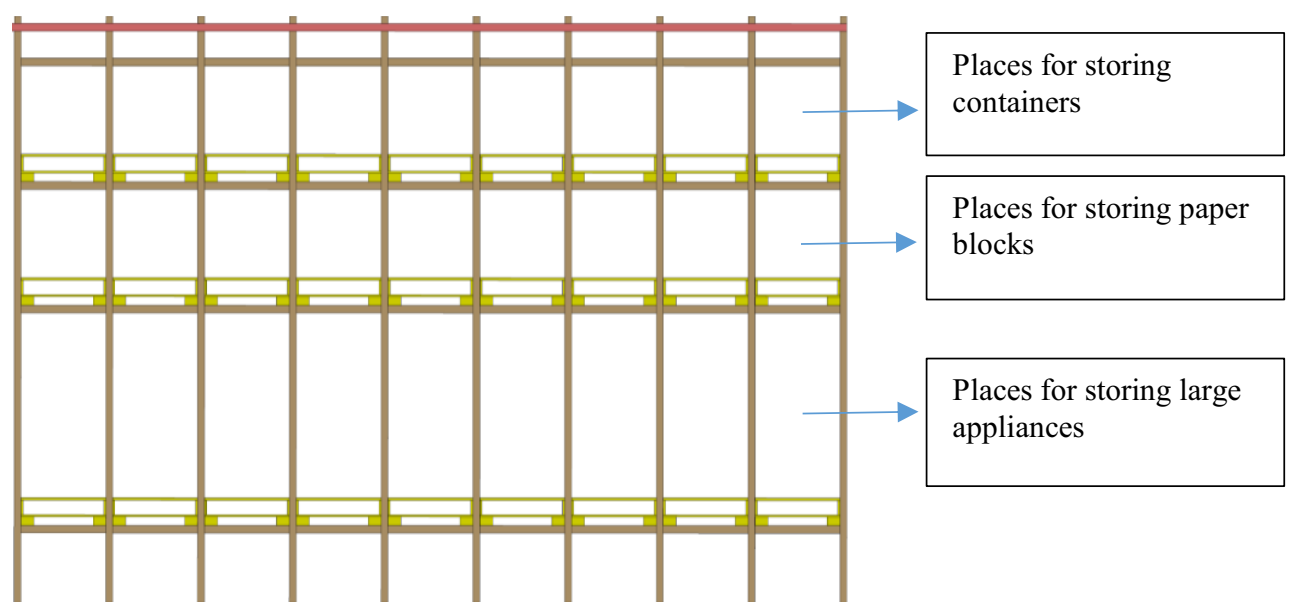

Fig. 5. Storage structure specific to the automated storage system

\subsection{Transport-transfer system}

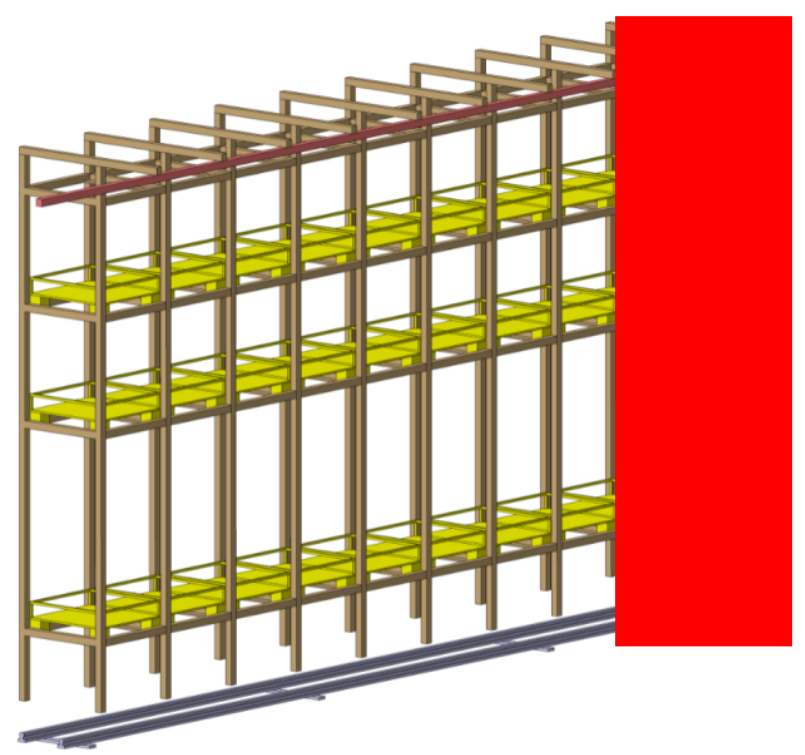

Fig. 6. The transport-transfer system 
The transport-transfer system (Figure 6) does the wastes storage and taking over operations when they are evacuated. Picking up waste process automation performed by the transport-transfer system is available through a couple of sensors mounted on input posts which confirm the presence and the type of the waste that is going to be collected and stored. The transport-transfer system can move vertically and horizontally to position the transfer system in the input and output stations and in the places of storage. It is made up of a rigid beam that can be moved vertically to the transfer system. The whole ensemble moves on the ground on a rail system that crosses the storage lane and a beam stiffened by the storage structure does the guidance.

The transfer subsystem takes over the WEEEs, the containers with waste and the compacted blocks of paper/cardboard from the input stations and disposes them in the places specific to the storage structure for the operation of loading and, respectively, that of taking over the waste stored from the places of storage and positions them in the output station for the discharging operation (waste disposal).

The transfer system is made up of two telescopic arms that are driven by an electric motor.
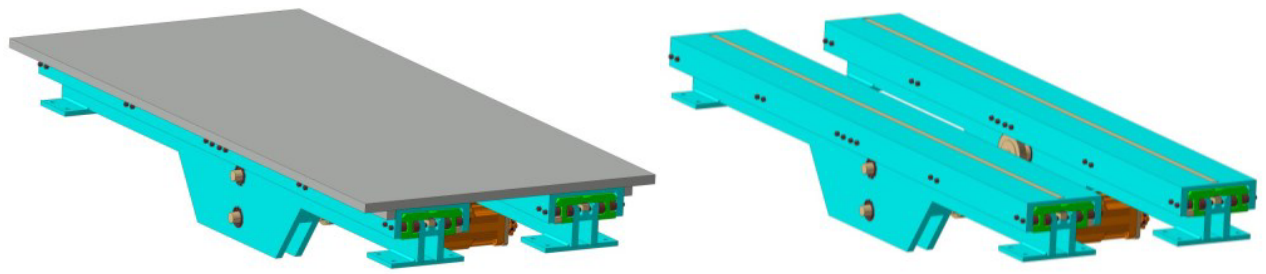

Fig. 7. The transfer system specific to the storage system

A telescopic arm consists of 3 sections (Figure 8). Segment 1 is fixed to the structure supporting the transport -transfer subsystem, segment 2 can move in relation to segment 1 up to its halfway point and segment 3 is can move in relation to Segment 2 up to its halfway point.

The operation of the two mobile segments is done through the pinion-rack mechanisms and the movement guiding is done through the buckets that are found on all the three segments.

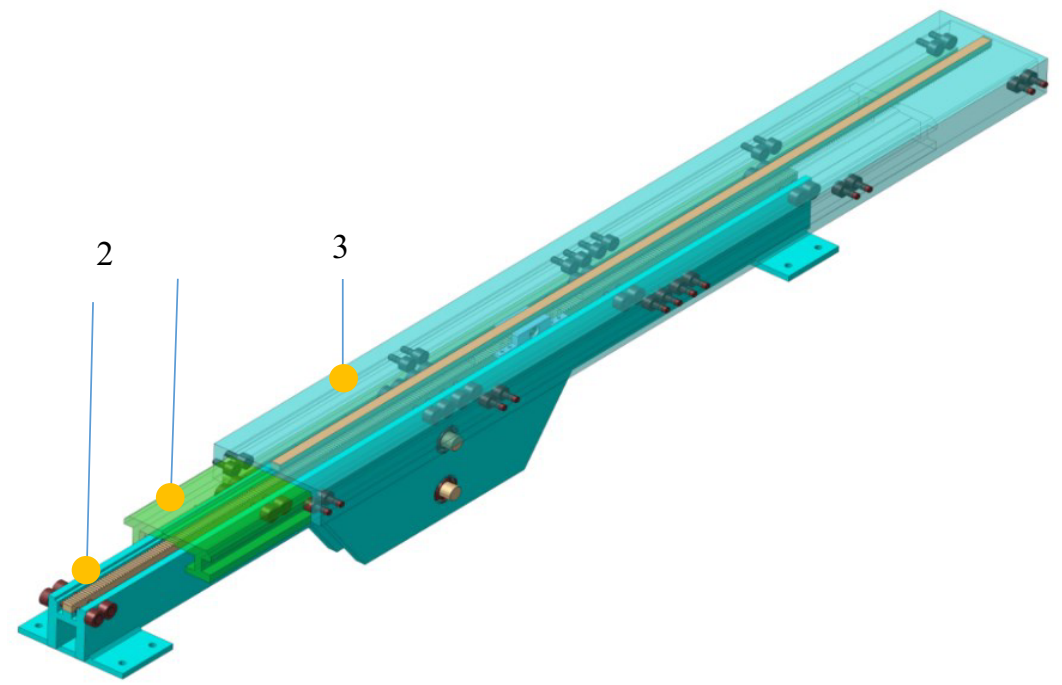

Fig. 8. The transfer system specific to the storage system 


\subsection{Input/Output stations}

The input stations are specific to the 4 areas of feeding with waste (large home appliances waste - input station 1; small home appliances waste positioned in the container - input station 2; cardboard and paper compacted into blocks and tied - input station 3; glass recipients, plastic recipients and aluminium cans positioned in the container - input station 4). Through these stations the transport-transfer system takes over the wastes and stores them. The input stations are arranged laterally along the whole length of the access lane specific to the transport-transfer system.

The output or evacuation station from the waste collection and storage system is placed in the continuation of the storage structure on the opposite side to the entrance stations. Qualified personnel do waste disposal in a scheduled order during the discharge.

\section{Conclusions}

The proposed structure for the waste collection and storage system takes over and stores large home appliances waste, small home appliances waste, cardboard, paper, glass recipients, plastic recipients and aluminium cans. This was made possible by the use of a support pallet positioned in each input station before or together with the collection container.

The virtual model designed by the authors is meant to be a part of the virtual model of the entire integrated waste collection system. The storage system structure will be integrated (in correlation with the technical specifications of the other types of equipment) in the imposed usable area of $60 \mathrm{~m}^{2}$ of the waste collection and storage system. The virtual model of the entire system will be the backbone of a digital twin, monitoring a modernized, completely automated waste collection system. This automated system, will considerably increase the waste collection level, will meet the requirements and the needs identified by the economic agent and will be ready to integrate the infrastructure of the smart city.

This work was supported by a grant of the Romanian National Authority for Scientific Research and Innovation, CNCS/CCCDI - UEFISCDI, project number PN-III-P2-2.1-BG-2016-0437, within PNCDI III.

\section{References}

1. B. Simon, M.B. Amor, R. Földényi, JCP 112, 11 (2016)

2. I. Ervasti, R. Miranda, I. Kauranen WM 48, 8 (2016)

3. F.C. Bergeron, RCR 115, 13 (2016)

4. C.E. Cotet, C.L. Popa, G. Enciu, A Popescu, T Dobrescu, IJSMM 15, 10 (2015)

5. C.A. Popescu, C.L. Popa, C.E. Cotet, G. Enciu, P DAAAM 27, 7 (2016)

6. R. Manzini, M. Gamberi, A. Regattieri IJAMT 28, 9 (2006)

7. C.A. Popescu, F.A. Nicolescu, G.C. Avram, A.M. Ivan, AMT 834, 6 (2016)

8. G. Enciu, J P ICMaS 1, 4 (2006) 